\title{
Docosahexaenoic acid and disulfiram act in concert to kill cancer cells: a mutual enhancement of their anticancer actions
}

\author{
Yang Jiao, ${ }^{1,2}$, Bethany N. Hannafon ${ }^{1}$, Roy R. Zhang ${ }^{1}$, Kar-Ming Fung ${ }^{1,3}$, Wei-Qun Ding ${ }^{1,3}$ \\ ${ }^{1}$ Department of Pathology, University of Oklahoma Health Sciences Center, Oklahoma City, OK 73104, USA \\ ${ }^{2}$ School of Radiation Medicine and Protection, Medical College of Soochow University, Suzhou 215123, P.R. China \\ ${ }^{3}$ Peggy and Charles Stephenson Cancer Center, Oklahoma City, OK 73104, USA \\ Correspondence to: Wei-Qun Ding, email: weiqun-ding@ouhsc.edu \\ Keywords: docosahexaenoic acid, disulfiram, oxidative stress, nuclear factor (erythroid-derived 2)-like 2, cancer stem cell \\ Received: June 17,2016 Accepted: December 16, 2016 Published: January 17, 2017
}

\section{ABSTRACT}

We previously reported a synergistic anticancer action of clioquinol and docosahexaenoic acid (DHA) in human cancer cells. However, clioquinol has been banned from the clinic due to its neurotoxicity. This study identified disulfiram (DSF) as a substitute compound to clioquinol, acting in concert with DHA to more effectively kill cancer cells and suppress tumor growth. Treatment with DSF and DHA induced greater apoptotic cell death and suppression of tumor growth in vitro and in vivo, as compared to DSF and DHA used alone. Mechanistic studies demonstrated that DSF enhances DHA-induced cellular oxidative stress as evidenced by up-regulation of Nrf2mediated heme oxygenase 1 (HO-1) gene transcription. On the other hand, DHA was found to enhance DSF-induced suppression of mammosphere formation and stem cell frequency in a selected cancer model system, indicating that alterations to cancer cell stemness are involved in the combinatory anticancer action of DSF and DHA. Thus, DHA and DSF, both clinically approved drugs, act in concert to more effectively kill cancer cells. This combinatory action involves an enhancement of cellular oxidative stress and suppression of cancer cell stemness.

\section{INTRODUCTION}

New drug combinations have been clinically and experimentally tested with the goal of improving cancer therapeutic efficacy and minimizing side-effects and drug resistance [1-4]. However, ideal combination therapies remain to be developed. In the course of searching for novel and effective combination therapies, we have previously reported that docosahexaenoic acid (DHA, $22: 6, n-3)$, a long chain $n-3$ polyunsaturated fatty acid (n-3 PUFA, Figure 1), and clioquinol, a metal binding compound act in synergy to kill human cancer cells $[5,6]$.

The anticancer properties of DHA have been well characterized in various experimental model systems [2, 7-9]. DHA is an essential long-chain n-3 PUFA that is beneficial to the health of the cardiovascular and central nervous systems [10-14]. DHAs' ability to selectively inhibit tumor cell viability while showing less toxicity towards normal cells, and its history of extensive and safe use in humans, justify DHA as a promising anticancer agent for combination therapy $[2,15]$. Mechanistic studies have implied that lipid peroxidation induced by DHA within tumor cells plays a crucial role in its anticancer action [16-18]. On the other hand, clioquinol is an antibiotic and metal binding compound that was reported to have anticancer activity in vitro and in vivo $[5,19,20]$. Historically, clioquinol was clinically used for treating diarrhea and skin infection. Unfortunately, it has been banned clinically in many countries because of its observed neurological toxicity $[21,22]$. Due to this limitation, we sought to find alternative compounds to clioquinol that may act in concert with DHA to more effectively kill cancer cells and suppress tumor progression.

DSF, a derivative of thiuram and a metal binding compound, has been safely used to combat alcoholism in human for more than sixty years with well characterized pharmacodynamics and kinetics (Figure 1) [23, 24]. Recently, its potential as an anticancer drug and as an adjuvant therapy has been tested both in preclinical studies and clinical trials [23, 25-27]. The mechanisms of DSF's anticancer effects are versatile. For example, 
serving as a metal binding compound of cellular heavy metal ions, similar to clioquinol, DSF impairs the activities of zinc- or copper-dependent enzymes, such as superoxide dismutases, matrix metalloproteinases, and inhibits proteasome activity, leading to inhibition of tumor angiogenesis, cancer cell invasion, and metastasis $[23,26,28]$. Interestingly DSF is considered as a metal ionophore [26, 28], a feature that has been well recognized for clioquinol [19, 29], In addition, DSF has long been recognized for its inhibitory activity against aldehyde dehydrogenase (ALDH), an enzyme having the strongest association with the cancer stem cell (CSC) phenotype [23]. Inhibition of ALDH activity by DSF has been reported to play a key role in suppressing the growth of CSCs derived from cancers of the brain, breast, ovary, pancreas, lung, liver, and blood [30-35]. Because DSF and clioquinol display similarity in metal ion binding and cellular sequestration $[26,28]$, we envisioned that DSF could serve as an excellent alternative compound to clioquinol, that can be tested for combination therapy with DHA.

We report here that DHA and DSF act in concert to more effectively kill cancer cells and suppress tumor progression both in vitro and in vivo. Our results suggest that this anticancer action is mediated in part through enhancing cellular oxidative stress and suppressing cancer cell stemness.

\section{RESULTS}

\section{DSF and DHA work together to more effectively induce apoptosis and suppress cancer cell growth}

DSF (Figure 1) and its metabolites can form strong complexes with endogenous heavy metal ions such as copper or zinc, resulting in inhibited activities of zincand copper-dependent enzymes (such as superoxide dismutase, matrix metalloproteinase, etc.), and in turn elevating cellular oxidative stress or impeding cancer cell invasion, angiogenesis, or metastasis [26, 36-38]. In the present study, we first confirmed that DSF's cytotoxicity was dramatically enhanced by copper or zinc ions. DSF alone exhibited its cytotoxicity on the human breast cancer cell line MDA-MB-231 at a relatively high concentration $(>1 \mathrm{mM})$, whereas its cytotoxicity was significantly increased in the presence of various concentrations of copper and zinc ions $(\mathrm{P}<0.05)$ (Figure 2$)$. These results are in accordance with the characteristic of DSF as a metal binding compound, similar to that of clioquinol [19, 39]. The enhanced cytotoxicity of DSF plus copper or zinc was also evident in several other human cancer cell lines (data not shown), including A2780 (ovarian), BT-20 and MCF7 (breast), suggesting that this is not a cell line specific effect.

The combination of DHA and clioquinol has been shown to significantly promote apoptotic death of human cancer cells [5]. To determine whether treatment with DSF and DHA enhances apoptosis of cancer cells, MDAMB-231 cells were exposed to $50-100 \mu \mathrm{M}$ DHA in the presence or absence of 10-30 $\mu \mathrm{M}$ DSF for $24 \mathrm{~h}$. PARP cleavage and procaspase 3 detection were measured for detection of apoptosis, as we previously described [5, 19]. Figure $3 \mathrm{~A}$ shows that the combination of DSF and DHA significantly enhances PARP cleavage and caspase-3 activation (shown by attenuated procaspase- 3 expression), results that are supportive of our hypothesis. To further affirm the combinatory effect of DHA and DSF on cancer growth, MDA-MB-231 cells were implanted to the flanks of nude mice using both aggressive $\left(5 \times 10^{6}\right.$ cells $)$ and less aggressive $\left(1 \times 10^{6}\right.$ cells $)$ models. The mice were
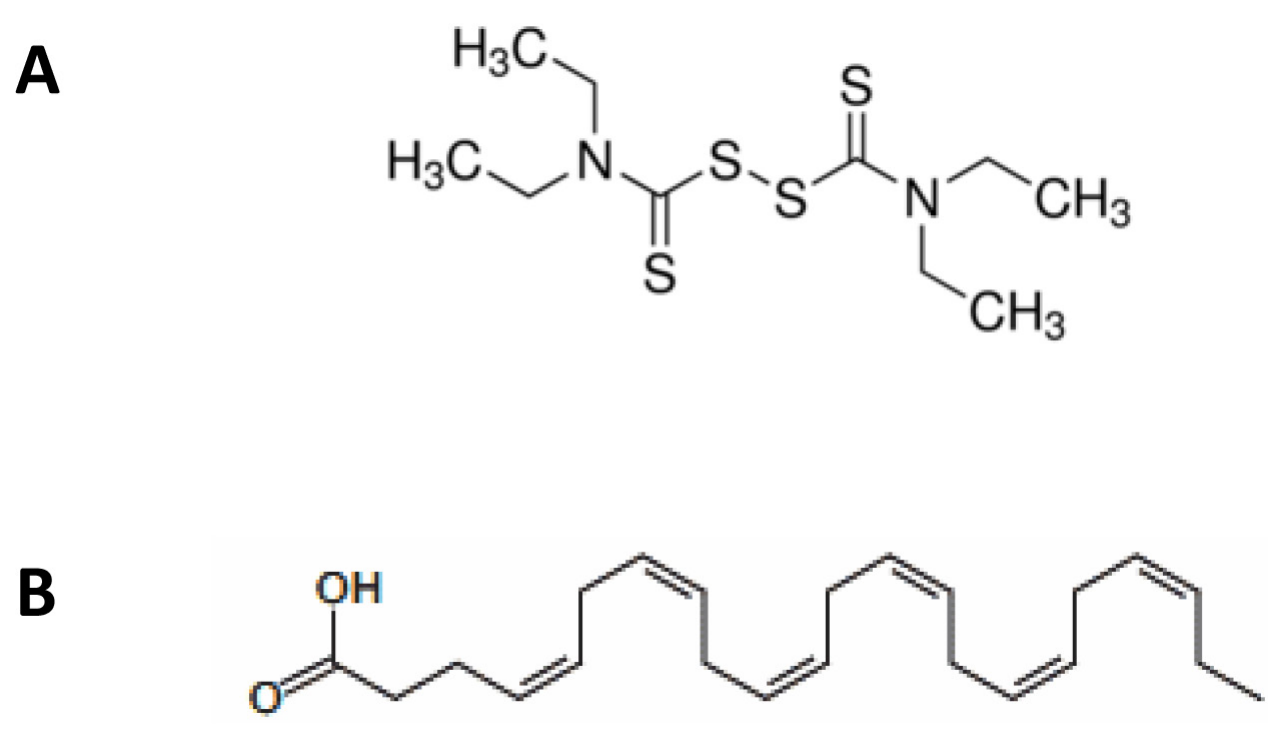

Figure 1: Molecular structure of disulfirm (DSF, A) and docosahexaenoic acid (DHA, B). 
fed a corn oil-based diet (7.5\%,wt/wt, high n-6 PUFAs) or a fish oil-based diet $(7.5 \%$, wt/wt, high n-3 PUFA (DHA), Table 1) [40]. DSF was delivered through I.P. at $75 \mathrm{mg} / \mathrm{kg}$. No significant difference of the body weight was observed among different groups of mice (data not shown). However, as shown in Figure 3B, as early as 14 days after DSF treatment in the less aggressive model, the tumor growth was significantly suppressed in mice fed with a fish oil-based diet compared to mice fed a corn oil-based diet $(\mathrm{P}<0.05)$. The significant suppression of tumor growth in fish oil fed mice was evident after 24 days of DSF treatment, and the trend lasted until the end of the experiment (Figure 3B, top). Furthermore, in the aggressive model, the tumor growth was significantly suppressed by DSF after 9 days of treatment in mice fed a fish oil diet as compared to mice fed a fish oil diet alone
$(\mathrm{P}<0.05)$, consistent with the observations from the less aggressive model.

Based on our previous experience with clioquinol and DHA [6], we assumed that the enhanced anticancer action by the combination of DSF and DHA would not be cell line specific. In fact the cytotoxic effects of the combination of DSF and DHA were also evident in A2780 and BT-20 cells (data now shown).

\section{DSF enhances DHA-induced HO-1 gene transcription}

We and others have previously demonstrated that DHA-induced lipid peroxidation in cancer cells is primarily accountable for DHA's anticancer activity [41]. We showed that in responding to DHA-induced

\section{A}

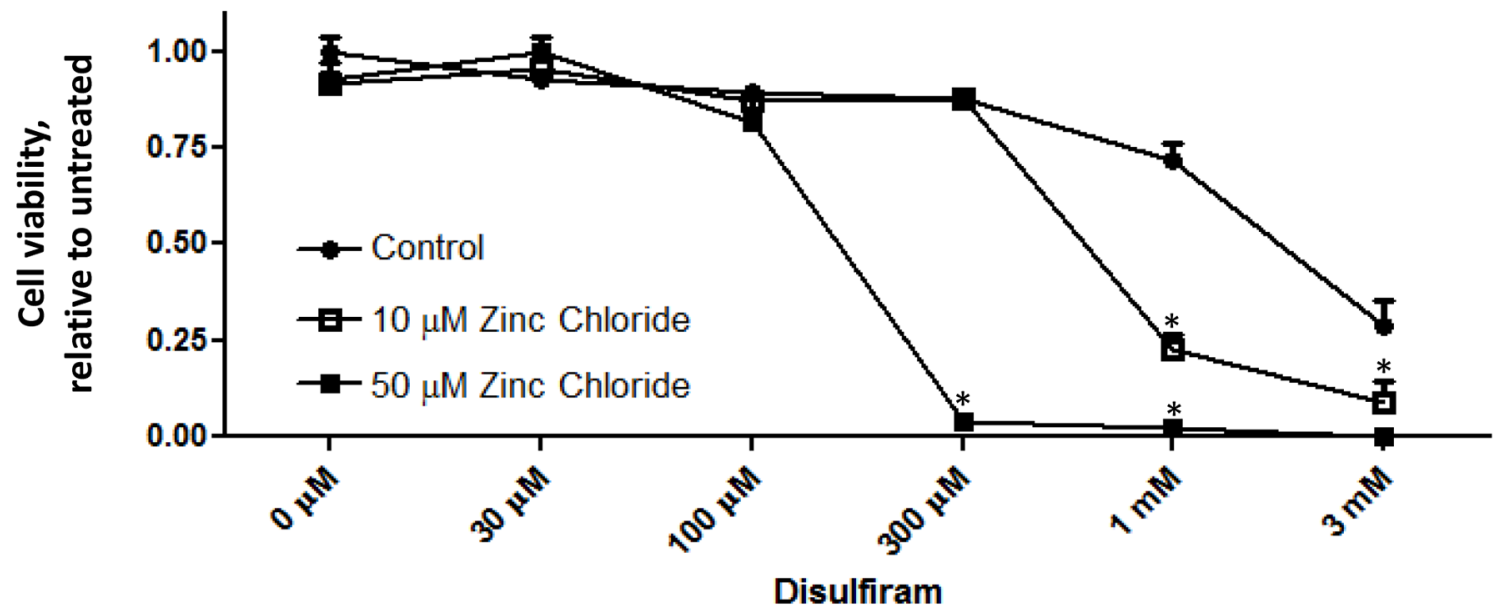

B

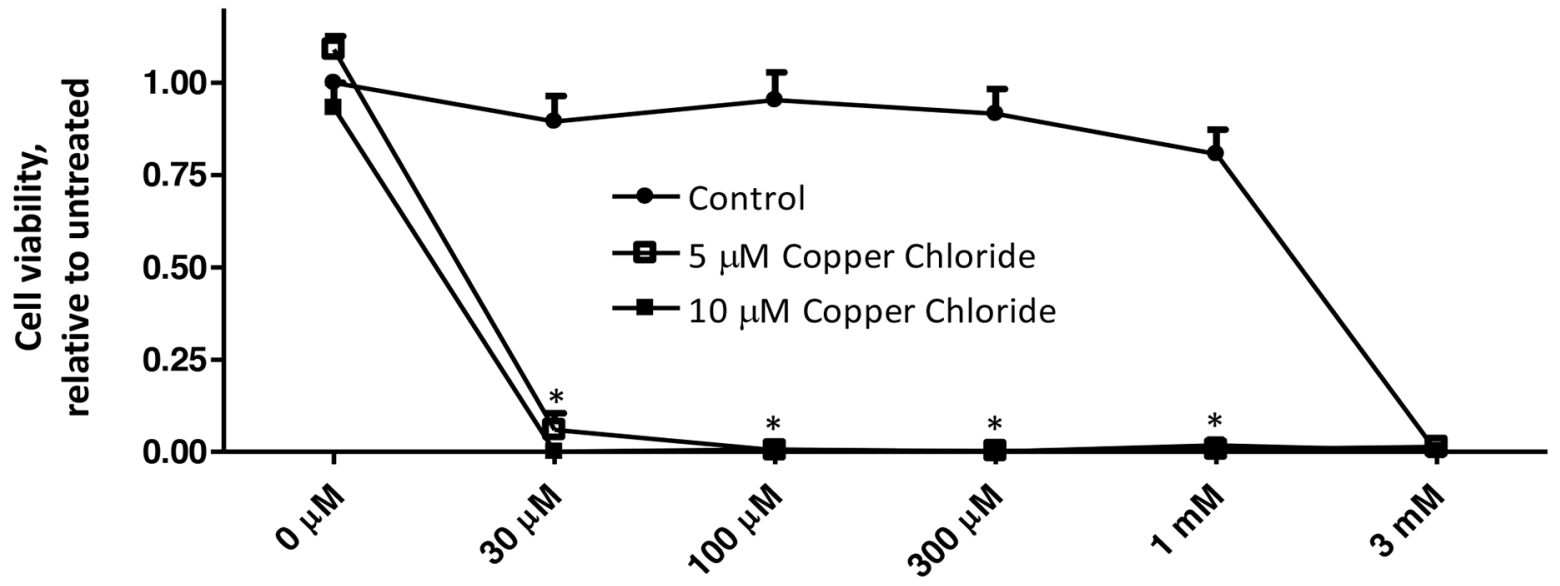

Disulfiram

Figure 2: Metal ions enhance DSF-induced suppression of cancer cell viability. MDA-MB-231 cells were treated with DSF, in the presence or absence of zinc chloride A. or copper chloride B. at the indicated concentrations for $72 \mathrm{~h}$. MTS assay was performed, and the representative result of three independent experiments was shown. Cell viability was expressed relative to untreated control cells. $* \mathrm{P}<0.05$, compared to untreated cells using one-way ANOVA. 
lipid peroxidation, the expression of heme oxygenase 1 (HO-1), a crucial cytoprotective antioxidant enzyme, is highly induced [40]. We therefore envisioned that the combination of DHA and DSF may enhance DHA's anticancer activity through augmenting DHA-induced oxidative stress. Indeed, we found that the HO-1 expression is significantly enhanced in cells that were treated with the combination of DHA $(50-100 \mu \mathrm{M})$ and DSF $(1-3 \mu \mathrm{M})$ as compared to cells treated with either compounds alone. This was analyzed by the reporter gene assay on HO-1 gene promoter activity (Figure 4A) and by western blot on HO-1 protein levels (Figure 4B, $4 \mathrm{C})$. The HO-1 protein expression was enhanced by the combination of DHA and DSF in a concentration- and time-dependent manner. Interestingly, DSF alone seemed able to induce HO-1 expression, an observation that has not been previously reported. Furthermore, an increased HO-1 protein expression was detected in xenograft tissues of the mice that were fed a fish oil-based diet and treated with DSF as compared to the mice without DSF treatment (Figure 4D). Taken together, both the in vitro and the in vivo results indicated that the combination of DSF and DHA enhances HO-1 expression in cancer cells. We have previously demonstrated that DHAinduced HO-1 gene transcription in A2780 cells is mainly regulated by the $\mathrm{Nrf} 2$ antioxidant pathway that targets the antioxidant responsive elements (ARE) localized in the HO-1 promoter region [40]. To determine whether this signaling mechanism also mediates DSF enhancement of the DHA-induced HO-1 expression, the HO-1 promoter reporter gene constructs, with or without deletion of the AREs, were transfected to A2780 cells. As shown in Figure 5A, deletion of the two AREs in the HO-1 gene promoter completely abolishes DHA-induced HO-1 gene transcription, regardless of the presence or absence of DSF, indicating the critical involvement of the Nrf2-ARE signaling in this event. The fact that DSF-induced HO-1 gene promoter activity was also abolished by the deletion of AREs suggested that oxidative stress is responsible for DSF-induced HO-1 gene expression. This was confirmed by the use of N-Acetyl Cysteine (NAC), an antioxidant reagent, which attenuated DSF-induced $\mathrm{HO}-1$ gene transcription $(\mathrm{P}<0.01$, Figure $5 \mathrm{~B})$. Both NAC and DSF failed to affect HO-1 3'UTR-mediated luciferase activity,
A
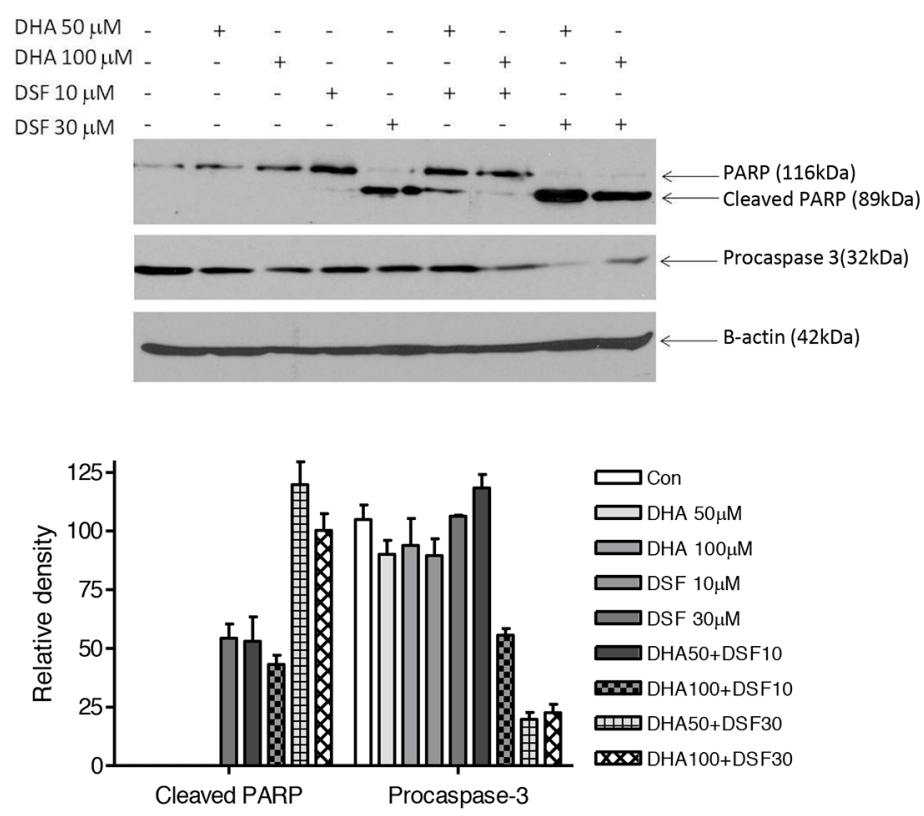

B
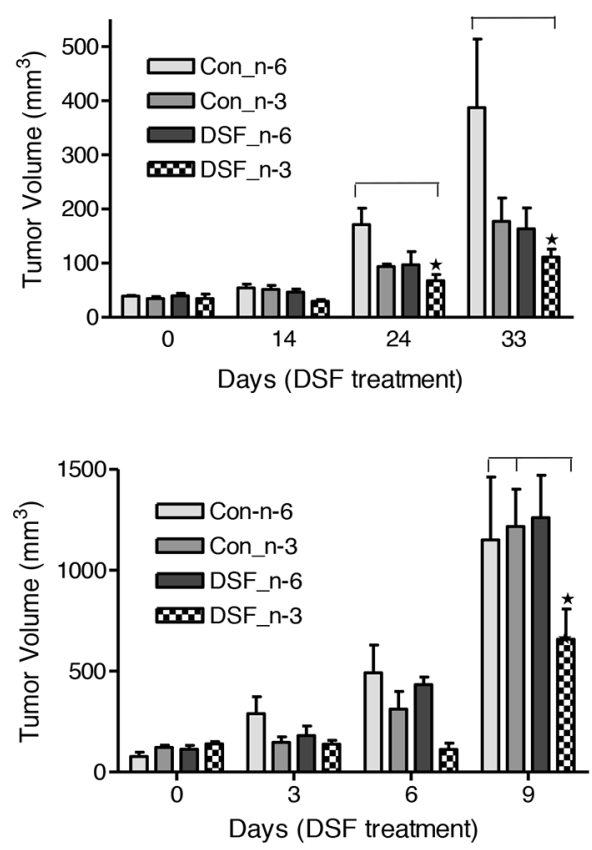

Figure 3: DSF and DHA work together to induce apoptosis and suppress tumor growth. A. MDA-MB-231 cells were incubated with DHA and/or DSF at indicated concentrations for $24 \mathrm{~h}$. Cell lysates were collected, and protein expression of PARP, procaspase-3, and $\beta$-actin was analyzed by Western blot assay (top). Expression of procaspase-3 and the cleaved PARP was quantified and normalized to $\beta$-actin (low, $n=3$ ). The data are expressed as percent of control group (procaspase-3) or percent of DHA $100 \mu \mathrm{M}$ plus DSF $30 \mu \mathrm{M}$ group (cleaved PARP). B. MDA-MB-231 cells $\left(10^{6} / 0.1 \mathrm{~mL}\right.$, less aggressive model, top) were inoculated into the left flank of 5-week-old female nude mice. The mice were fed with 7.5\% corn oil diet (high n-6 PUFA content) or 7.5\% fish oil diet (high n-3 PUFA content). Three weeks later, the mice were randomized into 4 groups and were treated with solvent or DSF (75 mg/.kg) for 4 therapeutic cycles. For an aggressive model, MDA-MB-231 cells $\left(5 \times 10^{6} / 0.1 \mathrm{~mL}\right.$, low) were inoculated into the left flank of 5-week-old female nude mice. The mice were fed with $7.5 \%$ corn oil diet (high n-6 PUFA content) or $7.5 \%$ fish oil diet (high n-3 PUFA content). One week later, the mice were randomized into 4 groups and were treated with solvent or DSF $(75 \mathrm{mg} / \mathrm{kg}$ ) for 5 days. Tumor volume was measured and calculated by the following formula: $\mathrm{V}=1 / 2\left(\mathrm{~A} \times \mathrm{B}^{2}\right)$, where $\mathrm{V}$ is the tumor volume, $\mathrm{A}$ is the length, and $\mathrm{B}$ is the width of the tumor $(\mathrm{n}=5)$. *,P $<0.05$, using Two-way ANOVA. 
Table 1: Composition of corn oil and fish oil diets $(\mathrm{g} / \mathrm{Kg})$

\begin{tabular}{lcc}
\hline Diet ingredients & Fish oil & Corn oil \\
\hline Casein & 200.0 & 200.0 \\
DL-Methionine & 3.0 & 3.0 \\
Sucrose & 475.0 & 475.0 \\
Corn Starch & 150.0 & 150.0 \\
Fish oil & 75.0 & 0.0 \\
Corn oil & 0.0 & 75.0 \\
Cellulose & 50.0 & 50.0 \\
Mineral Mix, AIN-76 & 35.0 & 35.0 \\
Vitamin Mix, AIN-76A & 10.0 & 10.0 \\
Choline Bitartrate & 2.0 & 2.0 \\
Ethoxyquin, antioxidant & 0.015 & 0.015 \\
Yellow food color & 0.1 & 0.1 \\
\hline
\end{tabular}

verifying that it is the HO-1 gene transcription that is affected by DSF. Together, these results, along with our previous reports [40], suggested that the HO-1 induction by DSF and DHA is mediated by oxidative stress targeting the Nrf2-ARE signaling pathway.

\section{DHA enhances DSF-induced suppression of cancer cell stemness}

DSF and its cellular metabolites have been well characterized for their inhibitory activity on ALDH [24]. Meanwhile ALDH has been generally accepted as a cancer stem cell (CSC) marker [42]. Accordingly, DSF's anticancer activity is considered to be associated with its inhibitory effect on cancer cell stemness among various types of malignancies [23, 30-33, 35]. In the present study, mammosphere formation [43] and in vitro Extreme Limiting Dilution (ELDA) assay [44, 45] were applied to determine whether DHA enhances DSF's suppression of cancer cell stemness. The human breast cancer cell line BT-20 was used for mammosphere formation in this study. Treatment with $10 \mu \mathrm{M}$ DSF or $50 \mu \mathrm{M}$ DHA alone minimally affected the appearance of the already formed mammospheres (Figure 6A); however the combination of DSF and DHA significantly decreased the mammosphere volume (Figure 6A, 6B). Furthermore, pretreatment with DSF alone for 48 hours significantly prevented mammosphere formation by reducing the mammosphere formation rate, indicating its ability to suppress cancel cell stemness (Figure 6C). When the cells were pretreated with DSF plus DHA, the formation rate of BT-20 mammospheres was completely depleted (Figure 6C). The in vitro ELDA assay was performed to confirm the effects of DSF and/or DHA on the cancer stem cell frequency. As shown in Figure 6D, a significant decrease in the cancer stem cell frequency was observed in cells pretreated with DSF and DHA, compared to those pretreated with each compound alone $(\mathrm{P}<0.001)$. The cancer stem cell frequency was $1 / 10.1$ in control cells, 1/85 in DSF/DHApretreated cells, 1/30.5 in DSF-pretreated cells, and 1/31.6 in DHA-pretreated cells. Taken together, these results illustrated that the suppression of cancer cell stemness by DSF is further enhanced by DHA, which offered another cellular mechanism to explain the enhanced anticancer activity by the combination of DSF and DHA.

\section{DISCUSSION}

We have previously demonstrated the synergistic anticancer actions of clioquinol and DHA [5]. However, further development of this combination therapy is impeded by the fact that cliquinol is neurotoxic and has been banned from clinical use in many countries [46-48]. We sought to find a substitute compound that may work with DHA as a potential combination cancer therapy. In this context, the most interesting finding from the present study is that we have identified DSF, a metal binding compound similar to clioquinol, that acts in concert with DHA to more effectively kill cancer cells. Because DSF has been used in humans for many years for the treatment of alcoholism [24], and DHA is a major component of fish oil supplements [49] and a prescribed drug [50], the combination of these two could be a promising strategy for more safe and effective cancer treatment.

We first confirmed that DSF acts as a metal binding compound to suppress cancer cell viability. DSF's cytotoxicity was dramatically enhanced by addition of copper or zinc ions indicating its similarity to clioquinol, belonging to a group of anticancer compounds, namely metal ionophores [29]. We then tested the anticancer action 

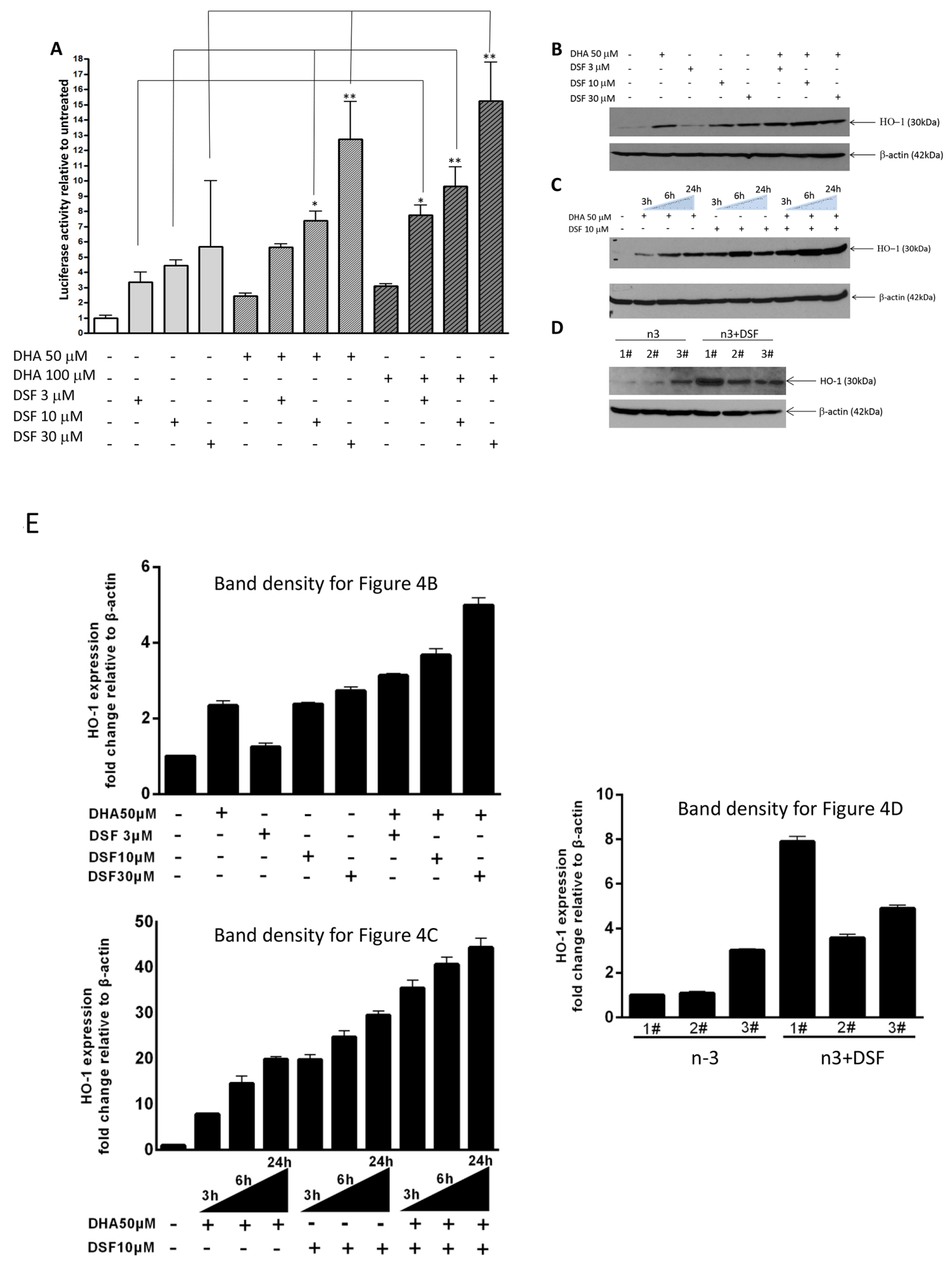

Figure 4: DSF enhances DHA-induced HO-1 gene transcription. A. MDA-MB-231 cells were transfected with the PGL3/HO-1promoter construct and treated with DHA $(50 \mu \mathrm{M}$ or $100 \mu \mathrm{M})$ in the presence or absence of DSF $(3 \mu \mathrm{M}, 10 \mu \mathrm{M}, 30 \mu \mathrm{M})$ for $21 \mathrm{~h}$. Luciferase activity was analyzed in the cell lysate and is expressed relative to the levels in untreated cells. *, $\mathrm{P}<0.05,{ }^{*}, \mathrm{P}<0.01$, versus untreated control cells using one-way ANOVA followed by Dunnett's analysis $(\mathrm{n}=4)$. B. MDA-MB-231 cells were treated with DSF $(3 \mu \mathrm{M}, 10 \mu \mathrm{M}$,

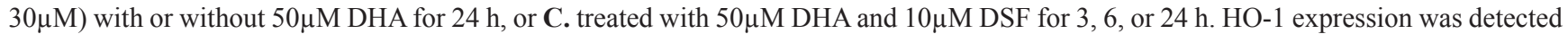
by Western blot. $\beta$-actin served as a loading control. D. HO-1 expression was detected by Western blot in tumor tissues from xenograft mice fed a fish oil diet (n-3) and treated with DSF (75mg/kg). $\beta$-actin served as a loading control. E. Expression of HO-1, detected in B, C and $\mathrm{D}$, was quantified and normalized to $\beta$-actin. 
of DSF plus DHA in different cancer model systems. Our experiments provide evidence to demonstrate a more effective anticancer action when DSF and DHA are used in combination. First, we show that DSF plus DHA more effectively induce apoptosis of human cancer cells, as evidenced by PARP cleavage and caspase 3 activation. These observations indicate that the combination of DSF and DHA can more effectively kill human cancer cells. Second, in a xenograft nude mouse model, we demonstrated that the combination of DSF treatment and a fish oil diet containing high DHA content significantly suppresses tumor growth as compared to mice with corn oil diet, thus providing in vivo evidence of an enhanced anticancer activity when DSF is combined with DHA. Note that the body weight is similar among groups of mice, suggesting that the combination of DSF and DHA is tolerable in vivo. The selective action of DSF with the fish oil diet versus corn oil diet is consistent with previous conclusions that n-3 PUFA, but not n-6 PUFA, suppresses tumor growth in various cancer model systems [51, 52]. Together, these observations clearly demonstrate that the combination of DSF and DHA is more effective in killing cancer cells and slowing down tumor growth.

In our search for potential cellular mechanisms behind the enhanced cytotoxicity of the combination of DSF and DHA, we assumed that either DHA's anticancer action is enhanced by DSF, or vice versa, that DSF's anticancer activity is enhanced by DHA. We discovered that the combination of DHA and DSF indeed leads to a mutual enhancement of their actions in cancer cells, including DHA-induced oxidative response, and DSFinduced suppression of mammosphere formation.

In our previous studies, we demonstrated that lipid peroxidation is primarily responsible for DHA-induced apoptotic cancer cell death [53]. Several studies also showed that the tumor suppressive effects of DHA may be accelerated by increased cellular oxidative stress [2, 17, 18, 54]. Coincidentally, DSF and its metabolites have been shown repeatedly to cause a pro-oxidative environment in cancer cells [17, 23, 26, 36]. Therefore, it is not surprising that the combination of DSF and DHA causes significantly higher oxidative pressure as indicated by enhanced HO-1 expression. Indeed, DSF alone could induce HO-1 transcription which can be attenuated by the antioxidant NAC, results consistent with the concept that DSF induces a pro-oxidative environment in cancer cells. Furthermore, in the absence of AREs in the HO-1 gene promoter, both DHA- and DSF-induced HO-1 gene promoter activity was abolished, further indicating that the Nrf2-ARE signaling, a well-established signaling pathway mediating cellular oxidative stress, is essential for this event. Thus, our results clearly indicate that cellular oxidative stress is enhanced by the combination of DSF and DHA which could lead to more effective killing of cancer cells

On the other hand, it has long been established that DSF has inhibitory activity against ALDH, specifically ALDH1A1 [24], and ALDH activity is highly associated with cancer cell stemness [42]. Therefore, the suppression of ALDH activity by DSF was thought to play a key role in its anticancer action [23]. In fact, DSF-induced suppression of CSCs has been extensively studied and well-recognized [23]. Meanwhile, in vitro and/or in vivo studies have confirmed that DHA also possesses the potential to eliminate CSCs [55-58]. Therefore, mammosphere formation and ELDA assay were applied to test whether DSF's inhibitory action on CSCs is enhanced by DHA.
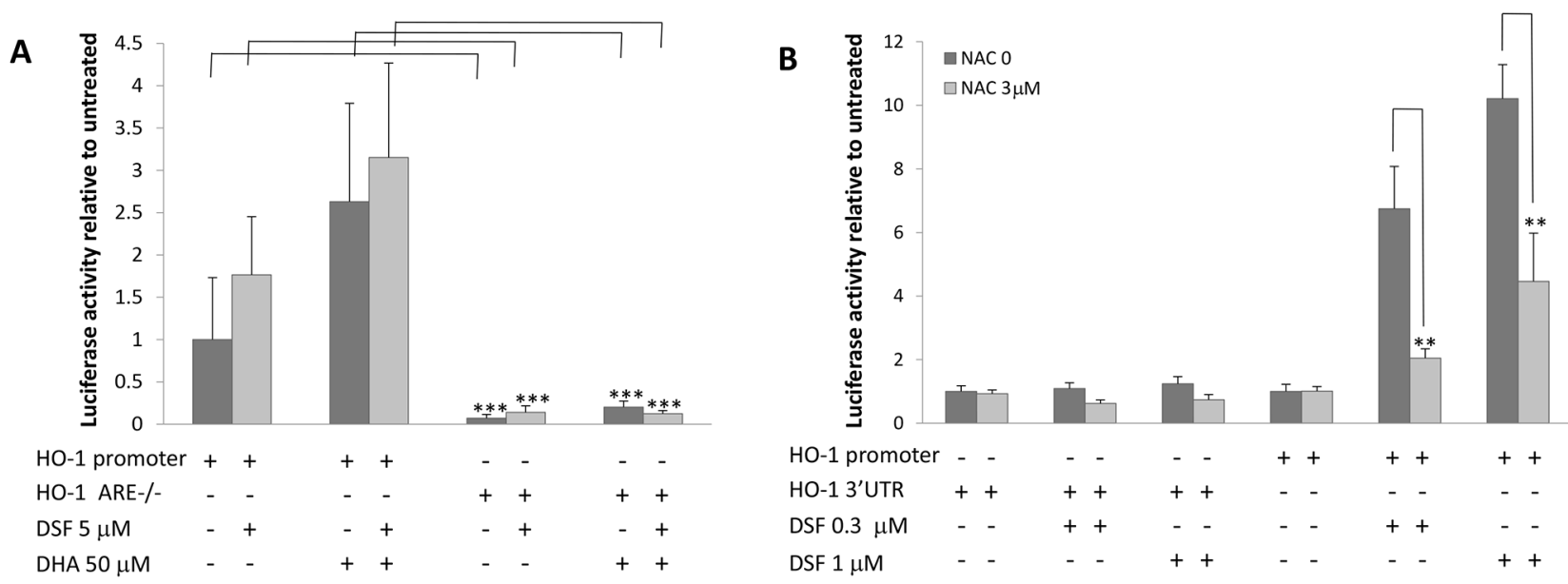

Figure 5: DSF enhances DHA-induced HO-1 gene transcription. A. A2780 cells were transfected with the PGL3/HO-1promoter or ARE double deleted HO-1 promoter constructs for $24 \mathrm{~h}$. The cells were then treated with $50 \mu \mathrm{M}$ DHA and $5 \mu \mathrm{M}$ DSF for $21 \mathrm{~h}$. The luciferase activity was analyzed $(\mathrm{n}=4)$. ***, $\mathrm{P}<0.001$, Student's t-test. B. A2780 cells were transfected with the PGL3/HO-1-promoter or PGL3/HO-1 3'UTR constructs for $24 \mathrm{~h}$, and treated with $3 \mu \mathrm{M}$ NAC for $1 \mathrm{~h}$ followed by DSF $(0.3 \mu \mathrm{M}$ or $1 \mu \mathrm{M})$ for additional $21 \mathrm{~h}$. The luciferase activity was analyzed $(\mathrm{n}=4) . * *, \mathrm{P}<0.01$, Student's t-test. 
A

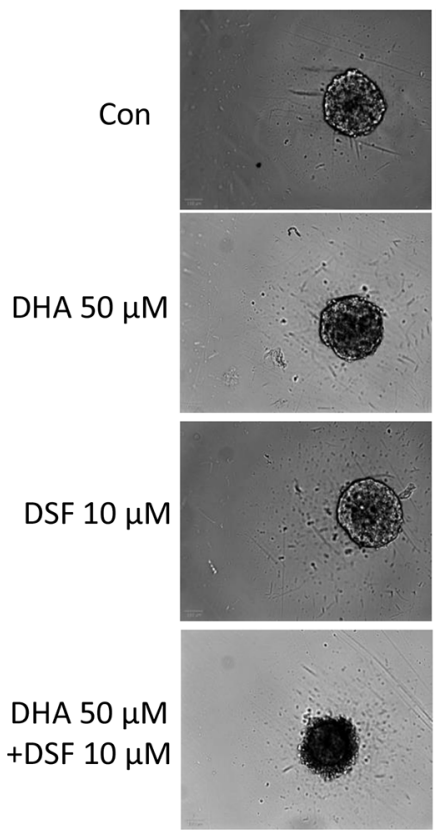

Day 3

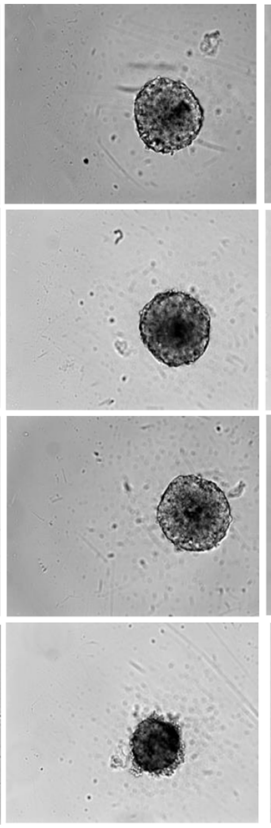

Day 5

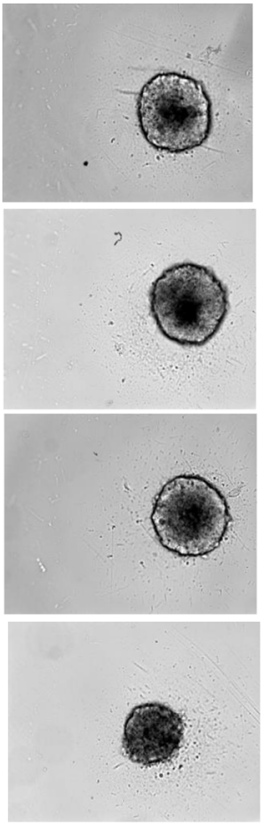

Day 7
B
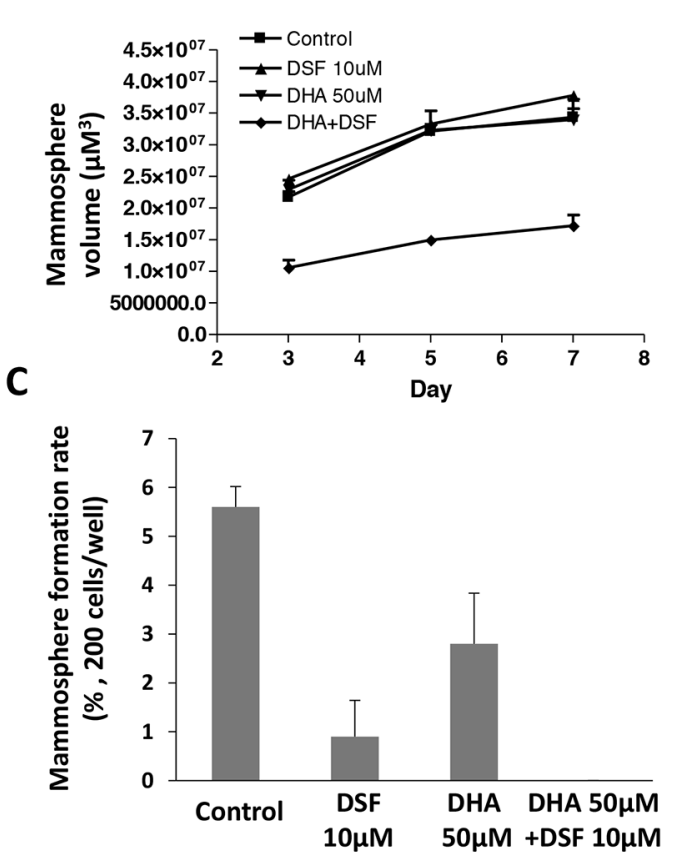

D

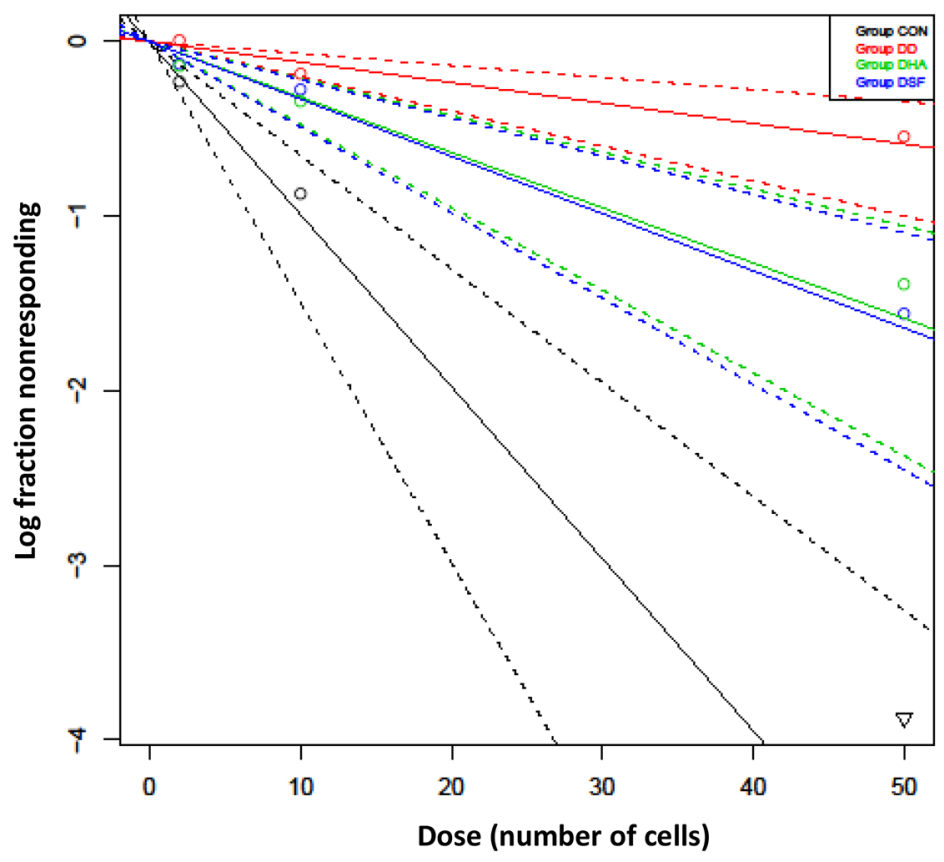

Estimated stem cell frequency

\begin{tabular}{|c|c|c|c|}
\hline \multicolumn{4}{|c|}{$\begin{array}{l}\text { Confidence intervals for } \\
1 / \text { (stem cell frequency) }\end{array}$} \\
\hline Group & Lower & Estimated & Upper \\
\hline A: Control & 15.3 & 10.1 & 6.7 \\
\hline B: DHA+DSF & 145.1 & 85.2 & 50.1 \\
\hline C: DHA $50 \mu \mathrm{M}$ & 47.3 & 31.6 & 21.1 \\
\hline $\mathrm{D}: \mathrm{DSF} 10 \mu \mathrm{M}$ & 45.6 & 30.5 & 20.4 \\
\hline
\end{tabular}

Overall test for differences in stem cell frequencies between any of the groups

\begin{tabular}{|c|c|c|}
\hline Chisq & DF & P. value \\
\hline 45.3 & 3 & $7.81 \mathrm{E}-10$ \\
\hline
\end{tabular}

Figure 6: DHA enhances DSF-induced suppression of mammosphere formation. BT-20 cells were seeded onto 96-well

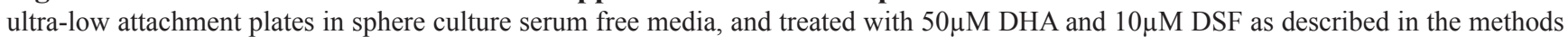
section. Mammosphere formation was observed and photographed using the PerkinElmer Operetta system A. The volume B. and formation rate $\mathbf{C}$. of mammosphere were analyzed. *, $\mathrm{P}<0.05$ versus untreated control using one-way ANOVA followed by Dunnett's analysis. D. The In vitro Extreme Limiting Dilution assay was performed $48 \mathrm{~h}$ after DHA and DSF treatment. Cells were plated into 96-well ultralow attachment plates with various seeding densities $(0.4-50$ cells/well in $200 \mu \mathrm{L})$ and were cultured until day 14 at $37^{\circ} \mathrm{C}$. At the time of quantification, each well was examined for the formation of mammospheres, and data were analyzed using extreme limiting dilution software web interface. 
It is well-known that cells derived from mammary tumors tend to form mammospheres under anchorageindependent conditions [59]. In the present study, although pre-formed mammospheres seemed to be unaffected by either DSF or DHA treatment, DSF pretreatment alone significantly suppressed the mammosphere formation rate, and the combined treatment of DSF and DHA further decreased both the mammosphere size and the formation rate, strongly indicating that the combination is more effective in suppressing cancer cell stemness. Theoretically, a single CSC is sufficient to form a mammosphere $[44,60]$; therefore the number of mammospheres after treatment represents the number of CSCs. We used the ELDA assay to statistically analyze the number of CSCs in each treatment regimen (DSF alone, DHA alone, and DSF/DHA combination) according to a Poisson distribution. The results demonstrate that the CSC frequency in both DSF and DHA treated breast cancer cells are reduced. A further reduction of the CSC frequency was observed in BT-20 cells pretreated with DSF and DHA. These data demonstrate that the combination of DHA and DSF suppresses mammosphere formation and stem cell frequency in a breast cancer model system, which could in part account for their combinatory anticancer action.

In summary, we have demonstrated that DHA and DSF act in concert to more effectively kill cancer cells and suppress tumor progression. The potential mechanisms behind their combinatory anticancer action include an enhancement of cellular oxidative stress and the suppression of cancer cell stemness. To our knowledge, this is the first attempt to explore the combined anticancer properties of these two compounds. Because both DSF and DHA are approved by the Food and Drug Administration for human use, further investigation on the potential of this combination therapy in clinical practice is warranted.

\section{MATERIALS AND METHODS}

\section{Cell culture and chemical compounds}

Human ovarian cancer cell line A2780, breast cancer cell lines MDA-MB-231 and BT-20 were purchased from American Type Culture Collection (ATCC, Manassas, VA, USA). A2780 cells were maintained in RPMI 1640 medium, while the breast cancer cell lines were cultured with DMEM medium, respectively. Growth medium was supplemented with $10 \%$ fetal bovine serum, 100 units/ml penicillin, and 100 units/ml streptomycin (Life Technologies Inc, Grand Island, NY, USA). Cells were cultured in an incubator with $5 \% \mathrm{CO}_{2}$ at $37^{\circ} \mathrm{C}$, and sub-cultured every other day. Analytic grade DSF, DHA, N-Acetyl-Cysteine (NAC), copper chloride, and zinc chloride were purchased from Sigma-Aldrich (St. Louis, MO, USA). The stock solution of DSF, DHA, NAC, copper chloride and zinc chloride was prepared in corresponding solvent as previously described [37, 61].

\section{MTS cell viability assay}

Exponential growth cancer cells were seeded onto 96-well plate at a density of 5,500/well. Twentyfour hours following seeding, cells were treated with various compounds as previously described [40]. The cells were cultured at $37^{\circ} \mathrm{C}$ with $5 \% \mathrm{CO}_{2}$ for additional $72 \mathrm{~h}$ after initiation of the treatment. For each well, the attached cells were incubated in $100 \mu \mathrm{L}$ growth medium supplemented with $20 \mu \mathrm{L}$ CellTiter $96 \AA$ AQueous One Solution (Promega, Madison, WI, USA) and incubated for $1 \mathrm{~h}$. The absorbance value at $495 \mathrm{~nm}$ was recorded using a spectrometer. The cell viability was calculated using the following formula: OD 490nm of treatment group/OD $490 \mathrm{~nm}$ of control group $\times 100 \%$.

\section{Western blot assay}

For whole cell lysate preparation, cells were mechanically detached from culture plates and collected by centrifugation at 3,000rpm for $5 \mathrm{~min}$ at $4{ }^{\circ} \mathrm{C}$, lysed in RIPA lysis buffer supplemented with the proteinase inhibitor cocktail (Roche, Indianapolis, IN, USA), and centrifuged at $13,000 \mathrm{rpm}$ to collect the supernatants. For nuclear protein extraction, cells were incubated with $2 \mathrm{~mL}$ wash buffer (1mM HEPES pH7.9, 0.15mM MgCl, $1 \mathrm{mM}$ $\mathrm{KCl}, 0.05 \mathrm{mM}$ Dithiothreitol, $0.01 \% \mathrm{NP}-40,1 \times$ proteinase inhibitor cocktail) on ice for $5 \mathrm{~min}$, and proceeded to centrifugation at 4000rpm for $5 \mathrm{~min}$. The supernatant was removed, and the cell pellet was incubated on ice for 30 min with $50 \mu \mathrm{L}$ suspension buffer $(25 \%$ glycerol, $0.42 \mathrm{M}$ $\mathrm{NaCl}, 1.5 \mathrm{mM} \mathrm{MgCl}_{2}, 0.2 \mathrm{mM}$ EDTA, $0.5 \mathrm{mM}$ DTT, $1 \times$ proteinase inhibitor cocktail), followed by centrifugation at $13000 \mathrm{rpm}$ for $20 \mathrm{~min}$ for nuclear protein collection. Western blot was performed as previously described [40]. In brief, $30 \mu \mathrm{g}$ proteins of each sample were separated by SDS-PAGE and transferred onto PVDF membranes (EMD Millipore, Billerica, MA, USA) under appropriate condition. Following blocking procedure by $5 \%$ non-fat milk, PVDF membranes were subsequently incubated in primary antibody solution, secondary antibody solution, washed, and finally proceeded to chemiluminescence (Thermo Scientific, Rockford, IL, USA) and X-ray film exposure (Denville Scientific Inc., Holliston, MA, USA). The primary antibodies used in this study were as follows: anti-PARP (1:1000, Cell Signaling Technology, Beverly, MA, USA), anti-Procaspase 3 (1:200, 31A1067, Santa Cruz Bio Technology Inc., Dallas, Texas, USA), anti-HO-1 (1:2000, Enzo Life Sciences, Farmingdale, NY, USA), anti$\beta$-Actin (1:5000, Sigma-Aldrich, St. Louis, MO, USA). The secondary antibodies were goat-anti-mouse IgG-HRP, goatanti-rabbit IgG-HRP (1:5000, Santa Cruz Bio Technology Inc., Dallas, Texas, USA). Protein expression of Procaspase 3, cleaved PARP, and HO-1, was semi-quantified by densitometry using Adobe Photoshop Elements 6.0 (San Jose, CA) and normalized to that of $\beta$-actin. 


\section{Human breast cancer xenograft mice experiment}

Five-week-old Balb/C nude mice were purchased from Taconic Farms Inc. (Germantown, NY) and used for the in vivo study. The research protocol was in accordance with the Institute Animal Care and Use Committee procedures and guidelines. One week before breast cancer cells inoculation, the mice were randomly divided into $7.5 \%$ fish oil diet and $7.5 \%$ corn oil diet (Teklad Diets, Madison, WI) groups, and fed with the assigned diet during the whole procedure. The human breast cancer cell line MDA-MB-231 was inoculated on the left flanks of nude mice at density of $10^{6} / 0.1 \mathrm{~mL}$ PBS-Matrigel for a less aggressive model, and $5 \times 10^{6} / 0.1 \mathrm{~mL}$ PBS-Matrigel for an aggressive model. Three weeks (less aggressive model) or one week (aggressive model) after inoculation for each diet group the mice were randomly divided into two subgroups (day 0), which were treated with DSF $(75 \mathrm{mg} / \mathrm{kg})$ or vehicle $(\mathrm{PBS} / \mathrm{Cremophor} / \mathrm{DMSO}=7.5 / 2 / 0.5)$ through I.P.. A 5-day consecutive daily injection was regarded as a treatment cycle, and all the mice in the less aggressive model were underwent 4 complete treatment cycles. One treatment cycle was completed for the aggressive model. Tumor volume was measured using the following formula: $\mathrm{V}=1 / 2\left(\mathrm{~A} \times \mathrm{B}^{2}\right)$, where $\mathrm{V}$ is the tumor volume, $\mathrm{A}$ is the length, and $\mathrm{B}$ is the width of the xenograft. The tumor volume and body weight were recorded 3 times a week. At the end of the experiment, the mice were euthanized. The tumors were excised and prepared for Western blot assay.

\section{Dual-luciferase reporter gene assay}

Dual-luciferase reporter gene assay was performed as previously described [40]. Briefly, cells were seeded onto $100 \mathrm{~mm}$ culture plates at a density of $2.2 \times 10^{6}$ and cultured overnight. The luciferase reporter constructs including the pGL3/4.5-HO-1 promoter, pGL3/4.5-HO-1 ARE mutants, and the HO-1-3'-UTR were applied for transfection using the Fugene HD transfection reagent (Roche, Indianapolis, IN, USA) [40]. Twenty-four hours after transfection, cells were re-plated into 96-well plates at a density of $1 \times 10^{5}$ per well. The following day, cells were treated with various compounds at indicated concentrations and durations. Luciferase activity was assayed using the Dual-Luciferase Reporter kit (Promega, Madison, WI, USA), according to the manufacture's instruction. The data was calculated as firefly/renilla for each sample and luciferase activity was presented as arbitrary units relative to untreated control cells.

\section{Mammosphere formation assay}

In order to determine the effects of DSF and/or DHA on the mammosphere formation ability, a BT-20 single cell suspension was cultured in 96-well ultra-low adherence plates (Perkin Elmer, Waltham, MA, USA) at a density of 2,000 cells $/ \mathrm{ml}$ with the stem cell medium, which was made of serum-free DMEM:F12 medium supplemented with B27 (Life Technologies Inc., Grand Island, NY, USA), $10 \mathrm{ng} / \mathrm{ml}$ basic fibroblasts growth factor, $5 \mu \mathrm{g} / \mathrm{ml}$ insulin, $0.4 \%$ BSA (Sigma-Aldrich, St. Louis, MO, USA), $2 \mathrm{ng} / \mathrm{ml}$ epidermal growth factor (Pepro Tech Inc., Rocky Hill, NJ, USA), and 100U/ml antibiotics (Life Technologies Inc., Grand Island, NY, USA). Five days after seeding, the mammospheres were exposed to drugs and cultured for another 7 days. The size of mammosphere was monitored and calculated every other day after drug treatment, using an Operetta high content imaging system (Perkin Elmer, Waltham, MA, USA). For mammosphere formation rate detection, BT-20 cells were pretreated with drugs for $48 \mathrm{~h}$, and then were sub-cultured in 96-well ultra-low adherence plates as described above. The mammospheres with the diameter greater than $40 \mu \mathrm{m}$ were counted under microscope 14 days after subculture. The mammosphere formation rate was presented as percentages of numbers of mammosphere/cells seeded.

\section{In vitro extreme limiting dilution assay}

The stem cell frequency was calculated by in vitro extreme limiting dilution assay (ELDA). Exponential growing BT-20 cells were pretreated with drugs for $48 \mathrm{~h}$, dissociated into single-cell suspensions, and were plated into 96-well plates in sphere culture media with various seeding densities $(0.4-50$ cells/well in $200 \mu \mathrm{L})$. The spheres were cultured for 10 days at $37^{\circ} \mathrm{C}$, and quantified for the frequencies of mammosphere formation at the end of the assay, using extreme limiting dilution software web interface (http://bioinf.wehi.edu.au/software/elda/).

\section{Statistics}

Statistical analysis was done with Graphpad Prism software (San Diego, CA, USA). Differences among control and experimental groups were determined by two tailed $T$ test or one-way ANOVA with Dunnett's posttest, with $\mathrm{p}<0.05$ or $\mathrm{p}<0.01$ as the level of statistical significance.

\section{Abbreviations}

ALDH, aldehyde dehydrogenase; ARE, antioxidant response element; CSC, cancer stem cells; DHA, docosahexaenoic acid; DSF, disulfiram; HO-1, heme oxygenase 1; NAC, N-Acetyl-Cysteine; Nrf2, nuclear factor (erythroid-derived 2)-like 2; PUFA, polyunsaturated fatty acid.

\section{CONFLICTS OF INTEREST}

We have no conflicts of interest to disclose. 


\section{FUNDING}

This work was supported in part by grants from the American Cancer Society (CNE-117557); the Susan G. Komen for the Cure Foundation (KG081083); and the Oklahoma Center for the Advancement of Science and Technology (HR14-147).

\section{Author's contributions}

YJ participated in the design of the study, carried out and/or supervised the experiments and drafted the manuscript. BNH, RRZ and KMF participated in the design of the study and helped to draft the manuscript. WQD conceived of the study, participated in its design and coordination, and helped to draft the manuscript. All authors read and approved the final manuscript.

\section{REFERENCES}

1. Sivanantham B, Sethuraman $\mathrm{S}$ and Krishnan UM. Combinatorial Effects of Curcumin with an Anti-Neoplastic Agent on Head and Neck Squamous Cell Carcinoma Through the Regulation of EGFR-ERK1/2 and Apoptotic Signaling Pathways. ACS combinatorial science. 2016; 18:22-35.

2. D'Eliseo D and Velotti F. Omega-3 Fatty Acids and Cancer Cell Cytotoxicity: Implications for Multi-Targeted Cancer Therapy. Journal of clinical medicine. 2016; 5.

3. Bukowska B, Rogalska A and Marczak A. New potential chemotherapy for ovarian cancer - Combined therapy with WP 631 and epothilone B. Life sciences. 2016; 151:86-92.

4. Yu XW, Lin S, Du HZ, Zhao RP, Feng SY, Yu BY, Zhang LY, Li RM, Qian CM, Luo XJ, Yuan ST and Sun L. Synergistic combination of DT-13 and topotecan inhibits human gastric cancer via myosin IIA-induced endocytosis of egf receptor in vitro and in vivo. Oncotarget. 2016; 7:32990-3003. doi: 10.18632/oncotarget.8843.

5. Ding WQ, Liu B, Vaught JL, Palmiter RD and Lind SE. Clioquinol and docosahexaenoic acid act synergistically to kill tumor cells. Molecular cancer therapeutics. 2006; 5:1864-1872.

6. Tuller ER, Brock AL, Yu H, Lou JR, Benbrook DM and Ding WQ. PPARalpha signaling mediates the synergistic cytotoxicity of clioquinol and docosahexaenoic acid in human cancer cells. Biochemical pharmacology. 2009; 77:1480-1486.

7. Eltweri AM, Thomas AL, Metcalfe M, Calder PC, Dennison $\mathrm{AR}$ and Bowrey DJ. Potential applications of fish oils rich in omega-3 polyunsaturated fatty acids in the management of gastrointestinal cancer. Clinical nutrition. 2016.

8. Zhelev Z, Ivanova D, Lazarova D, Aoki I, Bakalova $\mathrm{R}$ and Saga T. Docosahexaenoic Acid Sensitizes Leukemia Lymphocytes to Barasertib and Everolimus by
ROS-dependent Mechanism Without Affecting the Level of ROS and Viability of Normal Lymphocytes. Anticancer research. 2016; 36:1673-1682.

9. Zou S, Meng X, Meng Y, Liu J, Liu B, Zhang S, Ding $\mathrm{W}$, Wu J and Zhou J. Microarray analysis of anti-cancer effects of docosahexaenoic acid on human colon cancer model in nude mice. International journal of clinical and experimental medicine. 2015; 8:5075-5084.

10. Sperling LS and Nelson JR. History and future of omega-3 fatty acids in cardiovascular disease. Current medical research and opinion. 2016; 32:301-311.

11. Rodriguez-Perez C, Ramprasath VR, Pu S, Sabra A, Quirantes-Pine R, Segura-Carretero A and Jones PJ. Docosahexaenoic Acid Attenuates Cardiovascular Risk Factors via a Decline in Proprotein Convertase Subtilisin/ Kexin Type 9 (PCSK9) Plasma Levels. Lipids. 2016; 51:75-83.

12. Crawford MA, Golfetto I, Ghebremeskel K, Min Y, Moodley T, Poston L, Phylactos A, Cunnane S and Schmidt $\mathrm{W}$. The potential role for arachidonic and docosahexaenoic acids in protection against some central nervous system injuries in preterm infants. Lipids. 2003; 38:303-315.

13. Panickar KS and Bhathena SJ. (2010). Control of Fatty Acid Intake and the Role of Essential Fatty Acids in Cognitive Function and Neurological Disorders. In: Montmayeur JP and le Coutre J, eds. Fat Detection: Taste, Texture, and Post Ingestive Effects. (Boca Raton (FL).

14. Tang M, Zhang M, Cai H, Li H, Jiang P, Dang R, Liu Y, He X, Xue Y, Cao L and Wu Y. Maternal diet of polyunsaturated fatty acid altered the cell proliferation in the dentate gyrus of hippocampus and influenced glutamatergic and serotoninergic systems of neonatal female rats. Lipids in health and disease. 2016; 15:71.

15. de Aguiar Pastore Silva J, Emilia de Souza Fabre M and Waitzberg DL. Omega-3 supplements for patients in chemotherapy and/or radiotherapy: A systematic review. Clinical nutrition. 2015; 34:359-366.

16. Pogash TJ, El-Bayoumy K, Amin S, Gowda K, de Cicco RL, Barton M, Su Y, Russo IH, Himmelberger JA, Slifker M, Manni A and Russo J. Oxidized derivative of docosahexaenoic acid preferentially inhibit cell proliferation in triple negative over luminal breast cancer cells. In vitro cellular \& developmental biology Animal. 2015; 51:121-127.

17. Pettersen K, Monsen VT, Hakvag Pettersen CH, Overland HB, Pettersen G, Samdal H, Tesfahun AN, Lundemo AG, Bjorkoy $G$ and Schonberg SA. DHA-induced stress response in human colon cancer cells - Focus on oxidative stress and autophagy. Free radical biology \& medicine. 2016; 90:158-172.

18. Ding WQ and Lind SE. Phospholipid hydroperoxide glutathione peroxidase plays a role in protecting cancer cells from docosahexaenoic acid-induced cytotoxicity. Molecular cancer therapeutics. 2007; 6:1467-1474. 
19. Ding WQ, Liu B, Vaught JL, Yamauchi H and Lind SE. Anticancer activity of the antibiotic clioquinol. Cancer research. 2005; 65:3389-3395.

20. Schmitt SM, Frezza M and Dou QP. New applications of old metal-binding drugs in the treatment of human cancer. Front Biosci (Schol Ed). 2012; 4:375-391.

21. Konagaya M. [SMON: toxicity of clioquinol and the status quo]. Brain and nerve $=$ Shinkei kenkyu no shinpo. 2015; 67:49-62.

22. Kawamura K, Kuroda Y, Sogo M, Fujimoto M, Inui T and Mitsui T. Superoxide dismutase as a target of clioquinolinduced neurotoxicity. Biochemical and biophysical research communications. 2014; 452:181-185.

23. Triscott J, Rose Pambid M and Dunn SE. Concise review: bullseye: targeting cancer stem cells to improve the treatment of gliomas by repurposing disulfiram. Stem cells. 2015; 33:1042-1046.

24. Suh JJ, Pettinati HM, Kampman KM and O'Brien CP. The status of disulfiram: a half of a century later. Journal of clinical psychopharmacology. 2006; 26:290-302.

25. Calderon-Aparicio A, Strasberg-Rieber $M$ and Rieber $M$. Disulfiram anti-cancer efficacy without copper overload is enhanced by extracellular $\mathrm{H} 2 \mathrm{O} 2$ generation: antagonism by tetrathiomolybdate. Oncotarget. 2015; 6:29771-29781. doi: 10.18632/oncotarget.4833.

26. Allensworth JL, Evans MK, Bertucci F, Aldrich AJ, Festa RA, Finetti P, Ueno NT, Safi R, McDonnell DP, Thiele DJ, Van Laere S and Devi GR. Disulfiram (DSF) acts as a copper ionophore to induce copper-dependent oxidative stress and mediate anti-tumor efficacy in inflammatory breast cancer. Molecular oncology. 2015; 9:1155-1168.

27. Nechushtan H, Hamamreh Y, Nidal S, Gotfried M, Baron A, Shalev YI, Nisman B, Peretz T and Peylan-Ramu N. A phase IIb trial assessing the addition of disulfiram to chemotherapy for the treatment of metastatic non-small cell lung cancer. The oncologist. 2015; 20:366-367.

28. Wiggins HL, Wymant JM, Solfa F, Hiscox SE, Taylor KM, Westwell AD and Jones AT. Disulfiram-induced cytotoxicity and endo-lysosomal sequestration of zinc in breast cancer cells. Biochemical pharmacology. 2015; 93:332-342.

29. Ding WQ and Lind SE. Metal ionophores - An emerging class of anticancer drugs. IUBMB Life. 2009; 61:1013-1018.

30. Liu P, Brown S, Goktug T, Channathodiyil P, Kannappan V, Hugnot JP, Guichet PO, Bian X, Armesilla AL, Darling JL and Wang W. Cytotoxic effect of disulfiram/copper on human glioblastoma cell lines and ALDH-positive cancer-stem-like cells. British journal of cancer. 2012; 107:1488-1497.

31. Liu P, Kumar IS, Brown S, Kannappan V, Tawari PE, Tang JZ, Jiang W, Armesilla AL, Darling JL and Wang W. Disulfiram targets cancer stem-like cells and reverses resistance and cross-resistance in acquired paclitaxelresistant triple-negative breast cancer cells. British journal of cancer. 2013; 109:1876-1885.
32. Huang Y, Ju B, Tian J, Liu F, Yu H, Xiao H, Liu X, Liu W, Yao Z and Hao Q. Ovarian cancer stem cell-specific gene expression profiling and targeted drug prescreening. Oncology reports. 2014; 31:1235-1248.

33. Kim SK, Kim H, Lee DH, Kim TS, Kim T, Chung C, Koh GY, Kim H and Lim DS. Reversing the intractable nature of pancreatic cancer by selectively targeting ALDH-high, therapy-resistant cancer cells. PloS one. 2013; 8:e78130.

34. Duan L, Shen H, Zhao G, Yang R, Cai X, Zhang L, Jin $\mathrm{C}$ and Huang Y. Inhibitory effect of Disulfiram/copper complex on non-small cell lung cancer cells. Biochemical and biophysical research communications. 2014; 446:1010-1016.

35. Chiba T, Suzuki E, Yuki K, Zen Y, Oshima M, Miyagi S, Saraya A, Koide S, Motoyama T, Ogasawara S, Ooka Y, Tawada A, Nakatsura T, et al. Disulfiram eradicates tumorinitiating hepatocellular carcinoma cells in ROS-p38 MAPK pathway-dependent and -independent manners. PloS one. 2014; 9:e84807.

36. Bruning A and Kast RE. Oxidizing to death: disulfiram for cancer cell killing. Cell cycle. 2014; 13:1513-1514.

37. Shian SG, Kao YR, Wu FY and $\mathrm{Wu} \mathrm{CW}$. Inhibition of invasion and angiogenesis by zinc-chelating agent disulfiram. Molecular pharmacology. 2003; 64:1076-1084.

38. Salem K, McCormick ML, Wendlandt E, Zhan F and Goel A. Copper-zinc superoxide dismutase-mediated redox regulation of bortezomib resistance in multiple myeloma. Redox biology. 2015; 4:23-33.

39. Yu H, Zhou Y, Lind SE and Ding WQ. Clioquinol targets zinc to lysosomes in human cancer cells. Biochemical journal. 2009; 417:133-139.

40. Wang S, Hannafon BN, Wolf RF, Zhou J, Avery JE, $\mathrm{Wu}$ J, Lind SE and Ding WQ. Characterization of docosahexaenoic acid (DHA)-induced heme oxygenase-1 (HO-1) expression in human cancer cells: the importance of enhanced BTB and CNC homology 1 (Bach1) degradation. The journal of nutritional biochemistry. 2014.

41. Ding WQ, Vaught JL, Yamauchi H and Lind SE. Differential sensitivity of cancer cells to docosahexaenoic acid-induced cytotoxicity: the potential importance of down-regulation of superoxide dismutase 1 expression. Molecular cancer therapeutics. 2004; 3:1109-1117.

42. Pors K and Moreb JS. Aldehyde dehydrogenases in cancer: an opportunity for biomarker and drug development? Drug discovery today. 2014; 19:1953-1963.

43. Jiao X, Rizvanov AA, Cristofanilli M, Miftakhova RR and Pestell RG. Breast Cancer Stem Cell Isolation. Methods in molecular biology. 2016; 1406:121-135.

44. Hu Y and Smyth GK. ELDA: extreme limiting dilution analysis for comparing depleted and enriched populations in stem cell and other assays. Journal of immunological methods. 2009; 347:70-78.

45. Rota LM, Lazzarino DA, Ziegler AN, LeRoith D and Wood TL. Determining mammosphere-forming potential: 
application of the limiting dilution analysis. Journal of mammary gland biology and neoplasia. 2012; 17:119-123.

46. Cahoon L. The curious case of clioquinol. Nature medicine. 2009; 15:356-359.

47. Mao $\mathrm{X}$ and Schimmer AD. The toxicology of Clioquinol. Toxicology Letters. 2008; 182:1-6.

48. Meade TW. Subacute myelo-optic neuropathy and clioquinol. An epidemiological case-history for diagnosis. British journal of preventive \& socical medicine. 1975; 29:157-169.

49. Fabian CJ, Kimler BF and Hursting SD. Omega-3 fatty acids for breast cancer prevention and survivorship. Breast cancer research. 2015; 17:62.

50. Weintraub HS. Overview of prescription omega-3 fatty acid products for hypertriglyceridemia. Postgraduate medicine. $2014 ; 126: 7-18$

51. Grammatikos SI, Subbaiah PV, Victor TA and Miller WM. n-3 and n-6 fatty acid processing and growth effects in neoplastic and non-cancerous human mammary epithelial cell lines. British journal of cancer. 1994; 70:219-227.

52. Chajes V, Sattler W, Stranzl A and Kostner GM. Influence of n-3 fatty acids on the growth of human breast cancer cells in vitro: relationship to peroxides and vitamin-E. Breast cancer research and treatment. 1995; 34:199-212.

53. Wegiel B, Nemeth Z, Correa-Costa M, Bulmer AC and Otterbein LE. Heme oxygenase-1: a metabolic nike. Antioxidants \& redox signaling. 2014; 20:1709-1722.

54. Tuller ER, Beavers CT, Lou JR, Ihnat MA, Benbrook DM and Ding WQ. Docosahexaenoic acid inhibits superoxide dismutase 1 gene transcription in human cancer cells: the involvement of peroxisome proliferator-activated receptor alpha and hypoxia-inducible factor-2alpha signaling. Molecular pharmacology. 2009; 76:588-595.
55. Xiong A, Yu W, Liu Y, Sanders BG and Kline K. Elimination of ALDH+ breast tumor initiating cells by docosahexanoic acid and/or gamma tocotrienol through SHP-1 inhibition of Stat3 signaling. Molecular carcinogenesis. 2016; 55:420-430.

56. Yang T, Fang S, Zhang HX, Xu LX, Zhang ZQ, Yuan KT, Xue CL, Yu HL, Zhang S, Li YF, Shi HP and Zhang Y. N-3 PUFAs have antiproliferative and apoptotic effects on human colorectal cancer stem-like cells in vitro. The Journal of nutritional biochemistry. 2013; 24:744-753.

57. Yamagami T, Porada CD, Pardini RS, Zanjani ED and Almeida-Porada G. Docosahexaenoic acid induces dose dependent cell death in an early undifferentiated subtype of acute myeloid leukemia cell line. Cancer biology \& therapy. 2009; 8:331-337.

58. D'Eliseo D, Di Rocco G, Loria R, Soddu S, Santoni A and Velotti F. Epitelial-to-mesenchimal transition and invasion are upmodulated by tumor-expressed granzyme B and inhibited by docosahexaenoic acid in human colorectal cancer cells. Journal of experimental \& clinical cancer research. 2016; 35:24.

59. Charafe-Jauffret E, Ginestier C and Birnbaum D. Breast cancer stem cells: tools and models to rely on. BMC cancer. 2009; 9:202.

60. Chandrasekaran S and DeLouise LA. Enriching and characterizing cancer stem cell sub-populations in the WM115 melanoma cell line. Biomaterials. 2011; 32:9316-9327.

61. Wang S, Avery JE, Hannafon BN, Lind SE and Ding WQ. Zinc protoporphyrin suppresses cancer cell viability through a heme oxygenase-1-independent mechanism: The involvement of the Wnt/beta-catenin signaling pathway. Biochemical pharmacology. 2013; 85:1611-1618. 